\title{
EL CONCEPTO DE NACIÓN COMO SÍNTESIS EN LA OBRA REVOLUCIONARIA DE EMMANUEL SIEYÊS
}

\section{THE CONCEPT OF NATION AS A SYNTHESIS IN THE REVOLUTIONARY WORK OF EMMANUEL SIEYĖS}

\author{
Edgardo Rodríguez Gómez*
}

\section{Resumen}

El presente artículo esboza las coordenadas en las que se ubica intelectual y políticamente el abad de Sieyès, partícipe de las controversias que dieron lugar a dicho proceso histórico, como autor de una propuesta influyente y original, que recogería los intercambios polémicos de gente letrada compro-

* Doctorando en Estudios Avanzados de Derechos Humanos en la Universidad Carlos III de Madrid. Coordinador del Equipo Iniciativa RED CEPC Antiguos Alumnos, Coordinador del Consejo de Edición de Eunomía Revista en Cultura de la Legalidad editada por el Programa en Cultura de la Legalidad y publicada por Tirant lo Blanch. Becario de investigación en el Proyecto COOPtoFIGHT: The fight against trafficking in human beings in EU: promoting legal cooperation and victims' protection. Integrante del Grupo de Investigación sobre el Derecho y la Justicia, Personal colaborador de la Cátedra de Teología y Ciencias de las Religiones "Ignacio Ellacuría" de la Universidad Carlos III de Madrid. Secretario de la Asociación Iberoamericana Constitucionalismo y Democracia, miembro del Instituto Sur Andino de Derechos Humanos - ISADH, organismo afiliado a la Coordinadora Nacional de Derechos Humanos de Perú. Realiza la investigación doctoral en torno a la crítica de los argumentos de justificación de la guerra y la intervención bélica en nombre de los derechos humanos, en el área de Filosofía del Derecho. metida con el curso de la política reciente de su país, sea apoyando a la monarquía y sus ministros como dirigiendo críticas contra ésta en las distintas expresiones de la oposición al denominado "Antiguo régimen"; y pasa revista a las concepciones de nación que se aproximan a la propuesta de Sieyès, para distinguirlas y discernir la originalidad de su propuesta revolucionaria y en seguida efectuar un análisis de su contenido teórico, sin dejar de apuntar los detalles inacabados de su valiosa contribución a la historia del pensamiento político y constitucional.

\section{Palabras clave}

Nación - Constitución política - Político - Pensamiento - Democracia

\section{Abstract}

This article outlines the coordinates in which the abbot of Sieyès, who participates in the controversies that gave rise to this historical process, is the author and author of an influential and original proposal that would include the controversial exchanges of literate people committed to the course of his country's recent 
policy, either by supporting the monarchy and its ministers as critics against it in the different expressions of opposition to the so-called "Old Regime"; and examines the conceptions of nation that approach Sieyes's proposal, in order to distinguish them and to discern the originality of his revolutionary proposal, and to carry out an analysis of its theoretical content, while noting the unfinished details of its valuable contribution to the history of political and constitutional thinking.

\section{Keywords}

Nation - Political Constitution - Political Thought - Democracy

\section{Introducción}

La dimensión política y jurídica de la idea de nación perfiló sus alcances democráticos en pleno estallido de la revolución francesa, a finales de 1789. En un periodo de crisis social y ruptura institucional, el concepto de nación política (De Blas, 2003: 350-352) irrumpió con un significado novedoso para reconfigurar el desgastado vínculo entre el Estado moderno naciente y una sociedad que requería sentar las bases de un régimen inédito que se fundaba en los principios de libertad e igualdad.

A Emmanuel Sieyès, protagonista intelectual de la mayor de todas las fiebres hexagonales, le correspondería la tarea de formular las premisas ideológicas que servirán para afirmar la legitimidad jurídico-política de la autoridad en la representación nacional, aquella que se asienta en la nación formada por ciudadanos con derechos proscribiendo cualquier privilegio derivado de la pertenencia a órdenes y corporaciones; por lo que sitúa al individuo del "Tercer estado" como protagonista indiscutible de un diseño institucional capaz de concretar los logros de la construcción estatal desde el tránsito a la modernidad: indivisibilidad del poder y unidad del estado.

Interesa, por ende, (1) rastrear la evolución semántica de la idea de "nación" que se había ido instalando en el idioma francés hacía tres siglos atrás, y había permanecido vinculado a la monarquía en su periodo de mayor esplendor absoluto, revelándose a la postre como una clave para entender e idealizar un cambio social y político que se proyecta hasta la actualidad. Enseguida, resultará esclarecedor indagar (2) a qué aludía la nación en los cuarenta años previos al estallido revolucionario, y en plena Revolución, en algunas obras y opúsculos escritos, leídos y citados por filósofos y autores de panfletos de opinión, tanto apologéticos del gobierno como críticos, que rescatan en sus líneas el argumentario de la nación.

Asimismo, corresponderá (3) trazar las coordenadas en las que se ubica intelectual y políticamente el abad de Sieyès, partícipe de las controversias que dieron lugar a dicho proceso histórico, como autor de una propuesta influyente y original, que recogería los intercambios polémicos de gente letrada comprometida con el curso de la política reciente de su país, sea apoyando a la monarquía y sus ministros como dirigiendo críticas contra ésta en las distintas expresiones de la oposición al denominado "Antiguo régimen".

Finalmente, corresponderá también (4) revisar las concepciones de nación que se aproximan a la propuesta de Sieyès, para distinguirlas y discernir la originalidad de su propuesta revolucionaria para, enseguida, efectuar un análisis de su contenido teórico, sin dejar de apuntar los detalles inacabados de su valiosa contribución a la historia del pensamiento político y constitucional. 
1. La idea de nación del siglo XV al siglo XVIII en Francia

\section{a) Antes del siglo XVIII}

Los registros que aparecen durante la alta Edad Media en la evolución de la palabra "nación" -relacionada con la voz latina "nascere- asocian a ésta con la necesidad de identificación de un origen que puede ser compartido: el nacimiento en un espacio geográfico que constituye una referencia para el propio colectivo y para quienes no pertenecen a él. Su significado estará, por tanto, relacionado a un linaje y pronto dará cuenta también de la lengua hablada en aquel territorio. Se trataba ciertamente de una categoría más étnica que política que, no obstante, habría de constituir un insumo sustancial para la posterior formación de los modernos estados-nación (Gat, 2013: 212-219).

No resultó escasa la aportación de la iglesia católica en esa evolución, ya que hasta entonces se había erigido como la principal fuente de identidad colectiva -y universal- tras la caída del imperio romano. La iglesia en Francia contribuyó pronto a articular una necesidad de pertenencia que no se limitaría exclusivamente a la etnia, favoreciendo el despliegue de una identidad política al preparar y conservar - dice Touchard (2010: 178)- un marco territorial y administrativo para el nacimiento y desarrollo de las naciones modernas. Es decir, se opera el traslado de una referencia religiosa territorial, parroquial u episcopal, hacia un vínculo de pertenencia a la ciudad y al estado nacional.
El siglo XV devino decisivo en el proceso de la aparición de los primeros atisbos de una identidad nacional francesa de estricto carácter político. La Guerra de Cien Años dio lugar a un momento crucial en que fue indispensable acopiar una manifestación amplia de sacrificio colectivo procedente de un sentimiento común con algunas notas religiosas, pero definitivamente "pagano", que revelaba incluso ciertos indicios superadores de la estricta identificación con un monarca medieval primus inter pares. Alain Chartier (1923[1422]: 9-10) en Le Quadrilogue invectif dará cuenta de tal sensación clamando: "FRANCIA [...]... después del lazo de la fe católica, la Naturaleza os ha obligado ante todo a la común salvación del país de vuestro nacimiento y a la defensa de aquella señoría bajo la cual Dios os ha hecho nacer y vivir".

Pero este proceso no podía prescindir del monarca como elemento central de lealtad y fuente de la identidad francesa. Alguien podía asumirse francés añadiendo más rasgos a la fundamental sujeción al rey cristianísimo como hablar y escribir la lengua, sentir apego por la tierra o respetar sus costumbres y organización política. No era posible, entonces, identificarse como francés al margen de la relación entre rey y súbdito, como bien señala L. Greenfeld (2005: 139): "No se trataba de una identidad nacional."

$\mathrm{Al}$ ir delineándose los rasgos del estado moderno a lo largo del siglo XVI, como consecuencia del debilitamiento de la influencia de la iglesia 
en los asuntos estrictamente políticos de las monarquías cristianas y la consolidación cada vez más creciente del aparato burocrático abocado a cautelar los intereses del reino, en el fragor de nuevas guerras dinásticas que recurren ya a la artillería y la pólvora, Touchard (id.: 181) sugiere el surgimiento de una relación que deja de ser inminente entre el monarca soberano y la nación, estimando que se dan señales de una relajación en el vínculo entre el destino de ésta y la de su soberano cuando Francisco I, hecho prisionero tras su derrota en Pavía, se consuela con la idea de que "el honor de la nación está a salvo".

Una sugerencia que no recoge las textuales palabras del monarca y merece ser observada con detenimiento si se atiende a que con este rey renacentista se daría paso al inicio del proceso absolutista de la Corona francesa que hará de la figura del rey la representación corpórea de toda la nación.

En los siglos XVI y XVII se llevarán a cabo convocatorias a "Estados generales", una institución propia de la monarquía desde finales de la Edad Media que tenía por finalidad reunir ante el rey, cuando éste lo desease, a la "representación" del reino para que le asista con sus opiniones y le brinde consejo. Esta "representación" se entiende relacionada con la idea de solidaridades orgánicas: la familia, la comunidad, la corporación que gozan de derechos de carácter colectivo y alcance particular, resultando privilegios. La estructura que se configura ubica al rey de Francia situado en lo alto de una pirámide de jerar- quías subsumiendo y encarnando al conjunto de las corporaciones que constituyen la nación, conformando así un cuerpo único del cual el monarca es la cabeza única (Furet, 2007: 276).

El Parlamento de París jugaría también un papel trascendental en la configuración del sentimiento nacional, "mayor seguramente que el de los Estados Generales" -indica Touchard (íd.: 181). Desde finales de la Edad Media se irá haciendo fuerte una intuición manifestada más tarde por el jurista Charles Loyseau (1608: 113) que reconoce al Parlamento su contribución al evitar que Francia fuese dividida y desmembrada como Italia y Alemania "y que ha mantenido entero el reino".

Más aun, la importancia del Parlamento se puso en juego al juzgar y sentenciar asuntos que influirían para determinar los contornos de una identidad política francesa en contextos de guerra. Así, A. Bossuat (1950: 54-57) refiere estos dos caso: a) en 1437, Jeannette Roland, casada durante la ocupación inglesa con el inglés Gilbert Dowel fue sentenciada por el Parlamento disponiendo éste que no permitiría a la acusada marcharse con el apodado Westeford y así convertirse en inglesa durante la guerra; b) Una decisión más drástica recibiría una mujer que llegó a concebir hijos con un inglés, siendo declarada culpable de lesa majestad por lo que resultó privada de sus bienes. Dirá Bossuat que la ley natural, así como la ley canónica, deben ceder ante la necesidad nacional. 
b) Nación y absolutismo en el siglo XVIII

En pleno auge del absolutismo, el término nación era habitual en el uso de la lengua francesa durante los siglos XVII y XVIII; así se aprecia de las entradas que aparecen en los diccionarios de Furetière (1690: 710) y de Trévoux (1762: 10). El primero hacía referencia a una primera acepción que comprende "un gran pueblo que habita una cierta extensión de tierra, encerrada en ciertos límites o bajo un mismo dominio", señalando como ejemplos a los franceses o a los romanos de carácter belicoso. El segundo, repetiría la misma definición setenta años después.

Para entonces, gobiernan en Francia los Borbones, y el rey es indiscutiblemente un monarca absoluto; es decir, goza de la "summa potestas" que le atribuía Jean Bodin (1576) en Les six livres de la République, por ello no está sometido a las leyes al contar con el poder exclusivo de legislar ("puissance de donner et casser la loi”). Si la soberanía, según este autor podía ser teóricamente ejercida en regímenes diferentes: por el pueblo (democracia) o por un pequeño número (aristocracia), en Francia había encontrado su asidero más perfecto en la monarquía, y ello era verificable desde los "orígenes de la nación" (Furet, id.: 225).

El rey no sólo es fuente de toda legislación, también lo es de toda magistratura. Está en posesión temporal de la más alta autoridad sobre la tierra, por lo que sólo debe rendir cuentas a Dios, considerado auténtica fuente de toda ley humana. Pero no estaba sometido únicamente a las leyes di- vinas, debía adaptar su actuar estatal a un conjunto de principios de derecho público originados en la costumbre, a los que no podía "quebrar" y eran imprescriptibles. Se hallaban allí: las reglas de sucesión por orden de primogenitura masculina, la fe católica del soberano, la inalienabilidad del dominio real y las reglas de devolución de la corona, incluyendo las libertades de los súbditos y las corporaciones en las que se hallaban incluidos. Algún autor (Augé, 1979), incluso, ha llegado a considerar como una de tales leyes -de forma algo anacrónica- la denominada "regla de nacionalidad", que aludía a que el rey no podía ser extranjero.

En la primera mitad del siglo XVIII, el marqués de Boulainvilliers (1727: 5) exploraba como historiador los grandes acontecimientos protagonizados por la "nación francesa" en su Histoire de l'ancien gouvernement de la France -"de la Nation Françoise", apuntaba en el Prefacio- avec XIV lettres historiques sur les Parlements ou États-Généraux para concluir en una añoranza del pasado medieval en busca de una nación premoderna que debía quedar limitada a la nobleza: aquella descendiente directa de los francos conquistadores de la Galia. Como aclara Greenfeld (id.: 200): "Esto implicaba que la auténtica nobleza no podía adquirirse y que no le debía nada al favor de los príncipes."

La propuesta lanzaba un desafío claro al proceso de promoción y unificación de las élites al interior de una sociedad de órdenes que Luis XIV había hábilmente manejado, logrando con ello, durante su reina- 
do, uno de los más sólidos soportes para la construcción del Estado. Sin embargo, sus sucesores, Luis XV y Luis XVI, no fueron capaces de lograrlo, viéndose jalonados entre las exigencias de la administración estatal y su solidaridad con la aristocracia por ser descendientes de la familia más ilustre de la nobleza de Francia (Furet, íd.: 234). Ahora bien, aunque la sociedad aristocrática del siglo XVIII sería ampliamente obra de los Borbones, desde finales del siglo XVI los procedimientos para su éxito daban en parte razón a Boulainvilliers cuando se verifica que sus objetivos se habían alcanzado previa contraprestación con la venta de oficios, privilegios, estatus y rangos.

Ya al final de su reinado, Luis XV se veía obligado a dejar en claro su posición inquebrantable en relación con la nación dirigiéndose a otro actor clave de ese momento histórico que comenzaba a ser convulso: el Parlamento de París, que requería, hacia 1766, ejercer control sobre la autoridad soberana. "Es sólo a mí a quien pertenece el poder legislativo -dirá el monarca-, sin dependencia ni reparto.... es por mi única autoridad por la que los oficiales de mis tribunales soberanos proceden no ya a la formación, sino a la proclamación, publicación y ejecución de la ley" (en Richet, 1997: 41). Enseguida añadirá: “... el orden público, por completo, emana de mí... mi pueblo es uno conmigo y los derechos e intereses de la nación, de los cuales se pretende hacer un cuerpo separado del monarca, están necesariamente unidos a los míos y reposan únicamente en mis manos" (Furet, id.: 227).
El ingreso de Turgot en el gobierno, bajo el reinado de Luis XVI, cuestionará el orden de ideas anclado en el pasado. Para el fisiócrata e ilustrado hay un orden natural de las sociedades que es inteligible mediante la razón, por ende, se impone un deber de concretarlo. Atrás quedaban para él también las exigencias parlamentarias que buscaban soluciones que habrían de ser halladas en una constitución histórica donde reposaban derechos originarios de la nación opuestos a la ley. La monarquía, para Turgot, siendo coherente con la razón, se entiende como una copropiedad del rey y de todos los poseedores de bienes.

El diagnóstico es la ruptura entre estado y sociedad y la agonía del régimen. La solución debía estribar en representar los intereses de la sociedad, y no tanto en la voluntad jurídica de los asociados. Desde esta perspectiva, los parlamentos, con jueces que compran títulos y oficios, y así adquirieren privilegios, carecen de legitimidad para ser depositarios del mandato de velar por el bien común. Llegaba el momento de pensar en estructuras nuevas. Como concluye Furet (íd.: 244): "El proyecto permite comprender cómo la idea de la tabula rasa, que hará una brillante carrera revolucionaria, sale con naturalidad del antiguo régimen, fabricado por él."

\section{La nación, una idea revolucionaria}

\section{a) La patria y la nación}

Se ha ido mencionando hasta aquí referencias a la nación en Francia, intentando delinear su carácter político, sin plantearse una definición de 
lo que constituía la "nación francesa" en las circunstancias previas al momento revolucionario. Las investigaciones de L. Greenfeld (íd.: 213-230) ayudan para una aproximación en perspectiva histórica que den cuenta de dicha definición. Así, la idea de nación en el siglo XVIII francés pre-revolucionario, adquiere un halo positivo al inspirar cierta confianza puesto que bosqueja una "nueva jerarquía de valores" donde el estatus, al interior de la comunidad -entendida como nación- se confería teniendo en consideración el servicio que se prestaba a ella y el mérito.

Da la impresión que había llegado entonces el momento que anticipaba, quizá con demasiada antelación J. Touchard, cuando se van dando las condiciones que permitirán al estado, "alias la nación, alias el pueblo de Francia” (Greenfeld, íd.: 214), liberarse de su dependencia respecto del rey, para ganar el peso simbólico que servirá como aglutinante de una oposición a la monarquía, convirtiéndose en expresión legítima para reclamar cambios en la conducción estatal.

Los ilustrados participan de este esfuerzo cuando en la Encyclopédie (1765) aparecen publicados los artículos "Nation" y "Patrie" que constituye un intento por conciliar aproximaciones divergentes de ambos términos a fin de presentar un planteamiento teórico común. Lo que aparece finalmente son usos discrepantes de patria, ya politizados; mientras que nación ha conservado una cierta neutralidad (Delon, 1987: 131).
En un proceso que L. Greenfeld (id.: 218) denomina "La nacionalización del patriotismo", se parte por asumir que la patria es entendida como aquello a lo cual se aspira -lo que debe ser- mientras la nación es lo concreto -lo que es-. La patria representa la afirmación de valores mientras la nación implica una constatación tal como resulta definida por Didérot: "una cantidad considerable de población que habita en una cierta extensión de territorio, cercada por ciertos límites." En ese sentido, un dato destacable es la referencia a "cantidad considerable de población" opuesta al ideal de ciudad rousseauniana, lo suficientemente restringida para hacer posible una democracia directa.

Ahora bien, la Enciclopedia, a diferencia de lo que ya aparecía publicado décadas atrás en el Diccionario de Furetière, no había previsto la definición del adjetivo "nacional", aunque diez años más tarde, en el Supplément de la magna obra, la nación resultará elevada a fuente de legitimidad. Como explica Delon (íd.: 131-132), se recurrió al mismo tratamiento vinculado con la participación en la vida pública, que era una característica de la patria. Según se indica en el artículo "Celtas": “... los galos asociaban su felicidad a su independencia y a un "fanatismo republicano (...) Los jefes, limitados en sus poderes, no gozaban del derecho de infligir penas a los culpables. Ese derecho correspondía a la nación representada por sus magistrados". El concepto de nación ha adquirido así un potencial valor crítico. 
En 1770 se publica el Dictionnaire social et patriotique, ou Précis raisonné de connaissances relatives à léconomie morale, civique et politique a cargo de Pierre Lefèvre De Beauvray, protagonista de polémicas que más adelante se revisarán, al dar cauce a las exigencias parlamentarias contra el poder central. El "patriotismo" se levanta contra el despotismo en múltiples registros de los Cahiers de doléances que se elaboran en preparación de los Estados Generales de 1789. Es también el momento de esplendor de la palabra "nación”. En la línea de Turgot, Pierre-Louis de Lacretelle, en su panfleto De la convocation de la prochaîne tenue des États généraux, define a la nación como el conjunto de "ciudadanos que habitan un territorio, poseen una propiedad o cumplen con tareas esenciales para aquellos que cultivan la tierra, obedecen a las leyes, pagan los impuestos y sirven al país". H. Baysson (2002: 296), concluirá, algo apresuradamente, a partir de este texto que "con la Revolución, la idea de nación se va a restringir para limitarse sólo a los propietarios". Lo más acertado es considerar que requerirá de "ciudadanos activos", una elite social que reivindica la legitimidad política, Toda vez que, como apunta Delon (íd.: 132) será toda la población, la que poco a poco, devendrá en la nación, reclamando su participación en los asuntos públicos.

La nación, de este modo, se reunirá con la patria para dar cuenta de un pueblo que lucha, una colectividad que exige derechos "naturales" (Delon, íd.), para aparecer consagrado su nuevo significado en el artículo
III de la Declaración de los derechos del hombre y del ciudadano de 1789: "La fuente de toda soberanía reside esencialmente en la Nación".

b) Las incertidumbres de la nación histórica

La síntesis semántica que llegaría a alcanzarse entre patria y nación hubo de abrirse paso a través del vendaval de la "opinión". Ya en 1766, en la célebre "sesión de la flagelación", antes mencionada, Luis XV, monarca absoluto, fracasó en sus intentos de aplacarla y descalificarla. Para aquel rey, la discusión pública sólo podía tener cabida al interior de la estructura monárquica como expresión de la unidad política que decía reflejar pese a estar tachonada de particularismos. De pronto, la monarquía adquiría conciencia de su pérdida de autoridad sobre ese sector liberado de sus decisiones, pero susceptible de su influencia. Los intercambios de escritos mordaces entre jansenistas y parlamentarios dirigidos a sectores devotos y eclesiales pronto acogieron a apologetas de la Corona que "compra también defensores, paga plumas, financia panfletos, defiende su causa ante este nuevo tribunal." (Furet, id.: 238). Un tribunal público, opuesto al secretismo del monarca; universal, en contraste con el particularismo feudal; objetivo, contrario de la arbitrariedad monárquica.

Bajo el reinado de Luis XVI, los panfletos del librero Hardy sacaban de sus casillas al partidario de los filósofos -cercanos al sector ministerialLefebvre de Beauvray; el primero se situaba en las filas "patrióticas", próximas a jansenistas como Robert 
de Saint-Vincent -denostado por el segundo- crítico con jesuitas y filósofos a quienes denomina "incrédulos modernos". Se reeditan, entonces, querellas con antecedentes en 1771, combates apasionados de lo "patriótico" contra "la autoridad arbitraria" y el "despotismo oriental", en medio de la convocatoria a los Estados Generales (Van Kley, 2002: 474).

En medio del caos panfletario, el texto anónimo de tendencia jansenista titulado Suppléments aux remontrances du parlément de Paris, reúne de forma asombrosa las tesis opuestas hasta entonces de la soberanía nacional y la concepción aristocrática de la nación antes del otoño de 1788. Se trata de una señal evidente de un cierto acercamiento entre el discurso patriótico y el ministerial que podía anticipar lo que luego surgiría como un "partido nacional". Este paso inédito era indicativo de una pérdida de referencias cuando hacia finales de agosto e inicios de septiembre de 1788 se declara en quiebra la monarquía, cae Brienne de Lemoignon y se convoca a los Estados Generales.

Correspondía al Parlamento de París el registro de la declaración real de convocatoria de los Estados Generales, según -decía este cuerpo- "las formas de 1614". A partir de esta fórmula surge el riego de un malentendido "aristocrático" que pondría en alerta a los publicistas patrióticos, defensores de un constitucionalismo parlamentario riguroso. Los panfletarios ministeriales prevén entonces que cualquiera que fuere el sentido dado por el Parlamento a tal expresión, era sencillo concluir que las delegaciones de los órdenes convocados, nobleza, clero y Tercer estado, serían numéricamente iguales, votando cada uno de forma separada, comportando ello un espaldarazo a los intereses de la aristocracia.

Estos intereses aristocráticos comenzaron a verse favorecidos a inicios de diciembre, tras una segunda reunión de la asamblea de notables convocada por el nuevo ministro de Finanzas, J. Necker, para que aconseje al rey sobre las formas de convocatoria y composición de los Estados Generales. La asamblea no sólo interpretó mayoritariamente la fórmula en el sentido que los panfletarios antiparlamentarios habían imaginado con malicia, sino inclusive, superando sus previsiones, declaró que "incluso la nación reunida no tiene el poder de cambiar dichas formas" (Van Kley, íd.: 476).

Se habría de plantear en ese momento el debate sobre la posición del Parlamento de París en sus observaciones a los edictos de Turgot en 1776: "la distinción entre los órdenes forma parte de la Constitución histórica de Francia”. No obstante, con la intervención de la alta nobleza de la corte a través de la Memoria de los príncipes suscrita por el hermano del rey, Artois, junto a otros nobles de sangre, se vinculará a éstos de manera poco política a la defensa del trono y a la constitución aristocrática, lo que refuerza la idea que el constitucionalismo histórico sólo sirve a la causa de la aristocracia.

La respuesta de alguno de los más reputados defensores del constitucionalismo parlamentario, Jean-Baptis- 
te Turget, reconoce la existencia no sólo de uno, sino de "dos enemigos peligrosos que amenazan la felicidad y la libertad de las naciones: el despotismo ministerial y la aristocracia de las primeras clases". Comienza por ello a reclamar, junto con otros panfletarios, que se doble la delegación del Tercer estado y que el voto sea por cabeza (Van Kley, id.: 477).

Las condenas del despotismo y la aristocracia llevarán finalmente al cuestionamiento de las versiones patriótica y ministerial de la historia de Francia. Si la historia no atestigua libertad constitucional perdida alguna que pueda ser restaurada, ni beneficios que pueda garantizar una monarquía fuerte, ésta no sirve para nada y sólo es la evidencia de una larga "noche", como afirmaría Sieyès en ¿Qué es el Tercer Estado? La condena de la historia será el tema de innumerables panfletos "nacionales", a los que se dedican movimientos políticos como el célebre Comité de los Treinta, desde el otoño de 1788, vinculando a antiguos antagonistas patrióticos y ministeriales, y a adeptos confesionales, célebres panfletarios, como Cerruti o d'Aintraigues que harán llamados a una suerte de regeneración nacional.

Junto a la búsqueda de "regeneración", la expresión "lesa nación" aparece y es pronto difundida, entrando en vigor los efectos de su vulneración cuando luego de la sesión real del 23 de junio de 1789, Mirabeau proponga a los representantes de la nación investirse a sí mismos con los fueros de la inviolabilidad real (Van Kley, íd.: 479).
3. La nación como síntesis en la propuesta de Sieyès

a) De lo que prescinde: premisas opuestas de los partidos patriota y ministerial

El abad Emanuel-Joseph Sieyès, autor de Qu'est-ce que le tiers ètat?, ha captado pronto el escenario de oportunidad que haría posible dejar de lado las miradas al pasado y alcanzar una síntesis revolucionaria. Su atención puesta en los acontecimientos le permitirá ir desplegando sus reflexiones dialécticamente, como sucedía con quienes conformaban el "partido nacional", avanzando a través de síntesis históricas que registra y teoriza. Una primera que aparece en su obra es la que se concreta entre la tesis, hasta entonces exclusivamente patriótica, de la soberanía nacional y la antítesis ministerial de la nación compuesta de un Tercer estado que goza de derechos iguales. Sieyès recoge la referencia y prescinde, en consecuencia, de la tesis de la soberanía real y de la concepción de la nación como un "cuerpo" (Van Kley, íd.: 479).

En su primer panfleto previo a la Revolución titulado Ensayo sobre los privilegios, aparece una defensa de la tesis de la soberanía nacional en la que se reúne a los tres órdenes, recayendo en los ministros del reino la conducción del gobierno en nombre de la nación. En su segundo panfleto titulado Ideas sobre los medios de actuación de que podrán disponer los representantes de Francia en 1789, que es una reacción inmediata a las decisiones adoptadas por el Parlamento de París el 25 de septiembre 
de 1788, rechaza el principio de los privilegios, incluso honoríficos, para excluir a la nobleza de la nación, sin hacer referencia alguna a la soberanía nacional.

Finalmente, su tercer panfleto, ¿Qué es el Tercer estado?, recoge la síntesis de los dos previos desarrollando sus argumentos con precisión lógica y oportunismo político. Teóricamente inviste a la nación de un amplio poder para elaborar las leyes, definiéndola por contraste como entidad opuesta a todos los grupos privilegiados. No menos importante es su habilidad para dar una salida práctica a la necesidad de actuación del Tercer estado a quien corresponde aprovechar la ocasión de la reunión de los Estados Generales para declararse nación, dejando así de lado a los ministros del rey y a los órdenes privilegiados.

Las síntesis a las que llega Sieyès, pese a ser leídas con la claridad que proporciona el paso de siglos tras los acontecimientos, revelan su talento, especialmente cuando se observa que aquellas que otros ensayaban en el momento revolucionario no avizoraban objetivos tan claros. Tales síntesis, que se inspirarían en los contenidos desarrollados por los sectores patriota y ministerial, permiten en su momento una coexistencia de ambos aunque sus propuestas habrían de reflejar detalles que se revelaban en evidentes desacuerdos.

Un ejemplo de esto se aprecia en los escritos del exjesuita Cerruti, antes adepto pro-ministerial, quien en su Mémoire pour le peuple François se plantea "destrozar" a los "conspira- dores" parlamentarios que pretenden ser los legisladores de la nación y que, en la práctica, buscan restaurar una aristocracia feudal. Su posición pro-ministerial, sin embargo, se ve trastocada al favorecer la propuesta que sean los Estados Generales quienes elaboren la ley, pudiendo hacerlo con el rey o contra él. Todo ello lo señala, obviando dedicar mayores referencias a la soberanía nacional. (Van Kley, íd.: 480).

Puede echarse también un vistazo a los intentos fallidos de síntesis provenientes de los sectores patrióticos en los escritos del abogado Jean-Denis Lanjuinais, quien partiendo de su radicalismo en la lucha entre nobles y el Tercer estado, denuncia a la nobleza como "cuerpo parásito que vive de los trabajos del pueblo" y le recrimina su interés por someter a los Estados Generales a las "formas de 1614", mientras que sigue manteniendo como premisas para la solución de la crisis las contenidas en la doctrina constitucional anti-despótica o patriótica afirmada en la historia, que pide sea restablecida. En dicha constitución resulta imprescindible el "concurso del rey, de los grandes y del pueblo actuado a través de sus representantes" para que a través de sus deliberaciones se den los resultados de una voluntad general y constante cuya expresión será la ley por encima de todas las cabezas del reino (Van Kley, íd.: 481).

Ahora bien, aquello que podría denominarse la "síntesis nacional" no reagrupaba sólo a las tendencias patrióticas y ministeriales. Entre 1788 y 1789 , en el marco las elecciones a 
los Estados Generales, al ampliarse el programa de reformas ministeriales, irrumpen panfletos "individuales" que exhortan al rey y a los Estados Generales a terminar con las leyes civiles y penales, destruir los parlamentos, abrogar los derechos feudales, abolir la nobleza hereditaria, eliminar los beneficios eclesiásticos, confiscar o tasar los bienes de la iglesia, etc. No obstante, todos esos programas de reformas no dejaban de plantear el principio monárquico del "bon plaisir du roi", que debía ser respaldado por el Tercer estado, siempre presto a oponerse a los órdenes "privilegiados" (Van Kley, íd.: 481-482).

Esta es una muestra clara, en ese momento crítico, de la persistencia de un discurso ministerial anti-aristocrático que tiene asegurada la respuesta de un discurso patriótico anti-despótico, aunque modificado, que al ser enunciado generalmente por magistrados y abogados tiende a conceder el doble de representación a la delegación del Tercer estado e incluso en ocasiones el voto por cabeza, como parte de un simple juego táctico gatopardiano para dividir y conquistar ministros, sin modificar significativamente la suerte de aquellos a quienes Sieyès va avizorando ya como representantes de la nación.

\section{b) Lo que incorpora: el Tercer estado}

Por méritos propios la asamblea de Vizille, anunciaría en 1788, la importancia de Tercer estado en los acontecimientos que parecen protagonizar hasta entonces ministros y parlamentarios. Animados por un espíritu con visos revolucionarios, sus representantes provinciales no se limitan a reclamar antiguas franquicias que deben ser restauradas sino que trazan el plan de su actuación representativa en miras a la creación de una voluntad a escala nacional, dirigiendo sus primeros ataques efectivos contra la nobleza.

El siguiente movimiento que llevará a Vizille en la mente se concretará tras la convocatoria de los Estados Generales cuando nobles y parlamentarios rechazarían introducir cambios en el modo tradicional de designación "según las formas de 1614" de los representantes. El Tercer estado había logrado en la provincia que se doble su representación al mismo tiempo que su participación en sesiones compartidas.

El "partido nacional", contando en sus filas con aristócratas liberales, entra en escena organizando la campaña para lograr el objetivo de la doble representación del Tercer estado. Estos esfuerzos van creando un ambiente de esperanza, que alimenta la imaginación más allá de límites sociales, dirigido "hacia una nación reconciliada de veinticinco millones de ciudadanos" (Furet, íd.: 268-269). En ese momento, el Comité de los treinta coordina, sin monopolizar, un inmenso movimiento de opinión favorable a la campaña del que se hacen parte notables del Tercer estado junto a nobles como La Fayette o Talleyrand, junto a "tránsfugas" de sus respectivas clases como Mirabeau o Sieyès, lo cual inspira una reivindicación igualitaria.

Sieyès, sacerdote nacido en 1748 en el sur de Francia, hijo de una fami- 
lia burguesa modesta es un hijo de la ilustración, aspirando aproximarse a lo que acontece en la sociedad por la vía de la razón compatible con el interés general, planteará la fórmula maestra que llevará al Tercer estado a su identificación con la nación, a partir de tres cuestiones que marcarían el desenlace de la Revolución: "1. ¿Qué es el Tercer estado? Todo. 2. ¿Qué ha sido hasta ahora en el orden político? Nada. 3. ¿Qué pide? Llegar a algo."

En el Ensayo sobre los privilegios se ha involucrado ya con la denuncia de aquello que constituirá el móvil de la ira revolucionaria antes de su estallido, una nobleza cuyos privilegios la corrompe y hace de ella extranjera a la comunidad: "Desde el momento en que los ministros imprimen el carácter de privilegiado a un ciudadano, abren su alma a un interés particular y la cierran decididamente a las inspiraciones del interés común. La idea de patria se restringe para el privilegiado, reduciéndose a la casta a la que pertenecen" (Sièyes, 2007: 10). El privilegio coloca a quien los goza fuera de la esfera pública de la ciudad, provoca el impulso de proteger intereses particulares que hacen de su poseedor un individuo desprovisto de los atributos de la ciudadanía porque está embargado de la pasión de la dominación, de un amor propio exacerbado, de ser parte de otra humanidad. (Furet, íd.: 272). El resultado lógico será que al no ser parte del "todo", corresponde la exclusión de la nobleza como extraña a la nación.

En Ideas sobre los medios de actuación de que podrán disponer los repre- sentantes de Francia en 1789, Sieyès se concentra en los pasos a dar en los Estados Generales para lograr su transformación en Asamblea nacional constituyente. El desafío planteado es hacer efectiva la reunión de la nación para legislar. Tras plantear los principios de representación sobre la base de la idea de la división del trabajo propuesta por A. Smith, Sièyes (íd.: 42) dirá: "Un pueblo numeroso no puede, aún en menor medida, ejercer por sí mismo la voluntad común, su legislatura. Nombra, al efecto, representantes con la encomienda de actuar en su nombre, y no puede en modo alguno decirse que la voluntad común de estos representantes no constituya la verdadera ley, ni apruebe la ley para todos los ciudadanos". Le corresponderá aclarar que los mandatarios de su propuesta no constituyen representantes de fracciones del cuerpo social, sino que lo son de toda la nación soberana (Sièyes, íd.).

Pero es el contenido de ¿Qué es el Tercer estado? el que consagra a éste como la nación. Fisiócratas y economistas políticos influyeron en el autor para efectuar un tratamiento de la sociedad bajo la perspectiva de la actividad económica de sus integrantes, haciendo de ella el espacio en que se da lugar al progreso de la civilización mediante la producción de la riqueza (Furet, íd.: 273). Así, si existen clases útiles para tal fin, la nobleza no puede contar como parte de la sociedad estando impedida de ejercer profesión particular alguna, además, los cargos que desempeña pueden ser realizados por los integrantes del Tercer estado ya que "El 
Tercer estado, que había sido reducido a la nada, se ha reapropiado por medio de su industria una parte de lo que el pillaje del más fuerte le había arrebatado" (Sièyes, íd.: 108). La monarquía es culpable -y esclava- de la existencia de la aristocracia parásita, Sièyes no admite un juego de equilibrio entre ambos poderes favorable a la libertad de los individuos, pues ambos se alían en la dominación en función de intereses particulares por encima de los de la nación.

De ese modo, todos aquellos individuos, o el conjunto de ellos, comprometidos en la producción de la riqueza social o en el servicio público conforman una comunidad política a la que Sieyès denomina "nación", palabra nada nueva que alcanza su mayor dimensión revolucionaria y a la que al adscribírsele derechos se convirtió en instrumento contra el mal encarnado en el despotismo monárquico. En Sieyès (id.: 88), la nación es "un cuerpo de asociados viviendo bajo una ley común y representados por una misma legislatura". Es la voluntad constituyente, el contrato social concretado en su momento de fundación.

\section{La nación como concepto jurídico}

\section{a) La soberanía nacional en Sieyès}

Desencadenado el proceso revolucionario, la nación irá sustituyendo al rey como encarnación de la unidad estatal; lo cual quedaba reflejado en el lema de 1789: "La nación, la ley, el rey", representativo de un orden de prioridad donde a partir la base -la nación-, emana de la ley y la el rey constituye sólo una instancia de apli- cación (Delon, íd.: 132). En Sieyès, la idea de nación vacilaba entre hecho y valor; entre la posibilidad del reconocimiento de criterios objetivos y la adhesión a un ideal. Bajo esta dualidad, que también sintetiza en su obra, se hallan las pistas para rastrear las aportaciones del abad, en la elaboración de las nuevas premisas jurídico-políticas que debían permitir a la nación ejercer su propio poder como autoridad legítima.

Constituido el estado de ciudadanos, tras derogarse los privilegios, corresponde elaborar el Derecho que consagre garantías individuales e instituciones estatales, en función de una moral cívica. Es el momento- dice R. Máiz (2008: 28)- de la "producción de la Nación" como un cuerpo político unitario que se desenvuelve como un concepto propio de un segundo momento de la propuesta de Sieyès: El Estado-nación opera sobre la nación "reforzándola, unificándola y transformándola en "corps politique" a partir de la realidad social previa de los productores, mediante la centralización territorial, la educación nacional, la organización departamental, etc." (Máiz, íd.).

Sus efectos se revelan también en lo simbólico, la idea de nación reinventa símbolos: una bandera nacional, de tres colores cuando antes sólo era blanca, una fiesta nacional, consagrada el 14 de julio en remplazo de la fiesta de San Luis, celebración dedicada al rey, o un himno nacional. (Delon, íd.: 132).

El protagonismo de la nación resulta avasallador, la vía para el ejercicio de su soberanía -según señala el 
propio Sieyès en Sobre los acuerdos que deberán adoptar las asambleas, (íd.: 178)- se realizaba a través del Poder Constituyente, "que debe ser diferenciado, a toda costa, del Poder constituido". Era necesario institucionalizar la revolución para evitar la "insurrección permanente", dejando abiertos los cauces para la resistencia a un eventual despotismo que podrá ser enfrentado desde un marco constitucional mediante las denominadas "asambleas primarias".

La nación se purgaría también de los melancólicos de la etnia, como había sido Boulainvilliers a quien Sieyès (íd.: 89) refutó ya en ¿Qué es el Tercer estado? señalando: “¿Por qué no restituir a los bosques de Franconia a todas esas familias que conservan la desquiciada pretensión de ser descendientes de la raza de los conquistadores y haber heredado sus derechos de conquista? La nación, una vez depurada de aquellos, podrá consolarse, pienso, de saberse reducida a un conjunto de descendientes de galos y romanos. En verdad, si se quieren hacer distingos de origen ¿no podríamos asegurar a nuestros pobres conciudadanos que el que se remonta a galos y romanos posee por lo menos tanta alcurnia como el de sicambros, bárbaros ("welches") y otros salvajes salidos de los bosques y pantanos de la antigua Germania?"

Ahora bien, solo desde la lógica de síntesis del concepto de nación de Sieyès puede resultar plausible la simultanea coexistencia de sus significados que apunta R. Máiz (id.: 32): "1) una nación originaria, titular de la soberanía, que se traduce en el torrente revolucionario, legibus solutus, del poder constituyente: 'La nación que ejerce el poder constituyente debe encontrarse, en el ejercicio de esta función libre de todo constreñimiento y de toda forma...; y 2) a la vez, una nación construida que, una vez en el seno del Estado constitucional, pierde su soberanía en cuanto órgano constituido, pero no la libertad ni la capacidad participativa de sus miembros singulares, ante el imperio de la Constitución, que veta cualquier poder sin límites y reclama la libre participación en la génesis de la ley de aquellos que deberán de obedecerla."

En suma, “qué es la soberanía?” Se preguntaba Sieyès (íd.: 391) en Bases del orden social. No es, en todo caso, el resultado de la entrega de los asociados de todo cuanto les pertenece en manos de la comunidad haciéndose representar para la totalidad de sus fuerzas y de sus medios. En consecuencia, la soberanía -como poder supremo que domina y abarca todoen el marco constitucional no existe. R. Màiz (id.: 34) va más allá y deduce del estudio del pensamiento del autor "que, dentro del Estado constitucional democrático, no había lugar para soberano alguno: ni el Rey, ni el parlamento, pero tampoco la nación o el pueblo, todos ellos estando regulados y limitados por la norma constitucional."

A la nación le estará encargada una misión: ser titular y ejercer el poder constituyente como "poder latente y actualizable de modo excepcional en caso de quiebra despótica del Poder Público", advertirá Sieyès (id.: 387), 
además, no debe estarle autorizado delegar dicho poder bajo riesgo inminente de perder la libertad y de cambiar de Estado.

\section{b) Unidad y nación única}

El proceso de construcción estatal, en el que se inscribe la propuesta de Sieyès, acompaña a la institucionalización con mecanismos de unificación nacional. La nación constituida en principio y fin del Estado constitucional se vale de éste como "instrumento nacionalizador” (Máiz, id.: 28). Su estatuto jurídico-político ha prescindido del componente social que propició su advenimiento antes de resultar poder constituyente, aunque no renuncia a la conformación de una nación única a través de intervenciones asimiladoras y de "adunación" (Máiz, id.: 30).

Bajo este esquema, un estado con características centralistas se impone como una necesidad, especialmente si la nación ha prescindido en ese momento de la hipótesis externa del soberano y de la representación absoluta, siendo innegable un déficit de homogeneidad que demanda un proceso que, bajo la conducción del estado, procure la uniformización nacional. En consecuencia, observa Máiz (íd.: 30) "emerge la necesidad de la creación no solo de ciudadanos sino, en rigor, de franceses, o lo que es lo mismo, de Francia misma como Nación única (un seul tout)".

El argumento económico no deja de ser importante, pues una vez desterrados los privilegios concedidos a los nobles, habrá de hacer frente a la reaparición de identidades cultu- rales y lingüísticas existentes en las regiones del territorio que conforma Francia, y que se considerarán formas de particularismo en desmedro de la nación única, sólo asociada por el desempeño útil de tareas que ponen en juego intereses económicos más no identitarios.

Se va apreciando claramente que Sieyès (íd.: 294) está abocado a dar respuesta a las inquietudes de la nación post revolucionaria, superado ese momento en que a decir de De Blas (1984: 32) -siguiendo a E. Kemenka-: "El concepto básico de la Revolución francesa no es el de francés, sino el de ciudadano". Se hacen por tanto explícitas las premisas asimilacionistas y aunadoras que expresan sus esperanzas con estas palabras publicadas en las Observaciones sobre el dictamen del Comité de constitución: "Todos llevaremos algún día el nombre de franceses pudiéndonos sentir orgullosos de ello."

Planteada la tarea de la nación única, restará formular el marco teórico para representarla. Jurídicamente, la nación se ha condensado en un poder constituyente que asume como una de sus tareas primordiales el "reforzamiento" de la libertad individual, a partir de la cual se ha de formar una voluntad común que no es preexistente. Como resultado, aquellos que obedecen a la ley deben también concurrir en su formación.

Bajo este marco, las elecciones devienen imprescindibles para la representación, mientras los electores ostentan un derecho y el sufragio tiende a ser universal sin relación con la propiedad sino con la perso- 
na. Se añade a ello la regla de la mayoría para las decisiones ordinarias y la postulación se efectúa a partir de un sistema democrático mediante asambleas primarias que tienen por función concretar la participación y la deliberación, incluso para la revocación y radiación de los representantes, siendo además vías para el reingreso del poder latente de la nación cuando se presentan situaciones de despotismo o enmiendas a la constitución (Máiz, íd.: 37). Su propuesta, por ende, se alejaba de la que se consagró en la constitución de 1791 afirmada en la idea de mandato representativo y desvinculación entre representantes y representados.

Siendo el titular de la soberanía, como poder constituyente, la nación, el modelo representativo de Sieyès la consagrará como el fundamento primordial de su teoría política de características republicanas; al mismo tiempo que dejaba planteado como desafío al futuro la construcción de la nación única que también formaba parte de un proceso más largo de construcción del estado moderno en Francia.

El relativo éxito de su propuesta, a grandes rasgos, tras más de doscientos años de vigencia en el trasfondo republicano de la Francia actual, encara desafíos diversos a su teoría. Sus propias expresiones plasmadas en su obra fundamental, denuncian prejuicios, ya condenados por escritoras de su época que han devenido célebres tras siglos de olvido, y sus limitaciones para sobrepasar las barreras que impedían el acceso de las mujeres a la ciudadanía activa, sin consideración de mayores argumentos que la propia tradición que combatía: "En todos los países la ley ha fijado unos requisitos determinados, sin reunir los cuales no se puede ser ni elector ni elegible, Así, por ejemplo, la ley debe establecer una edad por debajo de la cual se estará incapacitado para representar a los conciudadanos. Por lo que a las mujeres respecta, éstas -bien o mal es otro problema en el que ahora no entraremos-, se ven alejadas por doquier de esta suerte de procuración" (Sieyès, id.: 98-99).

\section{Conclusiones}

1. Sieyès formó parte de aquellos intelectuales que se dedicaron a hacer efectivos los principios de la razón ilustrada, comprometiéndose en la tarea de desterrar ideas que resultaban incoherentes con la búsqueda de la felicidad y el interés general. Su método dialéctico conjugaba la constatación de hechos y la adscripción a valores. Al reflexiobar acerca de la nación, la patria representaba la afirmación de valores mientras la nación, que definiría políticamente, presentaba una constatación.

2. La síntesis como resultado metodológico a partir de un certero diagnóstico de los acontecimientos extraordinarios que vivía y su capacidad para teorizarlos, sin descuidar las posibilidades pragmáticas de sus ideas, convirtieron a Sieyès en un intelectual riguroso y acertado. En su definición de la nación recogería inicialmente la dialéctica entre la tesis de la soberanía nacional y la antítesis de una nación integrada por el Tercer estado, para decantarse por esta 
última, prescindiendo de la tesis de la soberanía real y de la concepción de la nación como un "cuerpo".

3. La nación, según Sieyès, estaría conformada por individuos, o el conjunto de ellos, comprometidos en la producción de la riqueza social o en el servicio público en una comunidad política. Sin tratarse de una palabra nueva, alcanza con él una dimensión trascendental al elaborarse en plena época revolucionaria. Será además la voluntad constituyente, el contrato social que se concreta en el momento de su fundación.
4. Con Sieyès, la idea de nación vacilaba entre hecho y valor, entre la posibilidad del reconocimiento de criterios objetivos y la adhesión a un ideal. Solo desde este presupuesto en la definición de la nación elaborada por este autor puede resultar plausible la simultanea existencia de una nación originaria, titular de la soberanía y poder constituyente y, al mismo tiempo, una nación construida que pierde su soberanía en cuanto órgano constituido, pero no la libertad ni la capacidad de participación de sus integrantes. 


\section{REFERENCIAS BIBLIOGRÁFICAS}

AugÉ, G.,

Succession de France et règle de nationalité: le droit royal historique français contre l'orléanisme, D.U.C, 1979, París.

BAysson, H.,

Idée d'étrager chez les philosophes de Lumières, L'Harmatan, 2002, París.

Bossuat, A.,

L'idée de nation et la Jurisprudence du Parlement de Paris au XVe siècle", Revue Historique, № 204, 1950, pp. 54-57.

Boulainvilliers, $\mathrm{H}$.,

Histoire de l'ancien gouvernement de la France avec XIV lettres historiques sur les Parlements ou États-Généraux, Tomo I, 1727, La Haya/Amsterdam.

Chartier, A.,

Le Quadrilogue invectif, Droz, 1923[1422], París.

De Blas Guerrero,

A. et al., Teoría del Estado, UNED, 2003, Madrid.

De Blas Guerrero,

Nacionalismo e ideologías políticas contemporáneas, Espasa-Calpe, 1984, Madrid.

Delon, M.,

"Nation", en Ory, P. et al., Nouvelle histoire des idées politiques, Hachette, 1987, París, pp. 127-135.
Furet, F.,

La Révolution française, Gallimard, 2007, París.

Furetière, A.,

Dictionnaire universel contenant generalement tous les mots françois, tant vieux que modernes, \& les termes de toutes les sciences et des arts, Tome II, Chez Arnout \& Reiner Leers, 1690, Rotterdam.

GAT, A.,

Nations: The Long History and Deep Roots of Political Ethnicity and $\mathrm{Na}$ tionalism, Cambridge University Press, 2013, Cambridge.

GREenfeLD, L.,

Nacionalismo. Cinco vías hacia la modernidad, CEPC, 2005, Madrid.

MÁrz, R.,

La frontera interior. El lugar de la nación en la teoría de la democracia $y$ el federalismo, Tres fronteras ediciones, 2008, Murcia.

MÁrz, R.,

Nación y revolución. La teoría política de Emmanuel Sieyès, Tecnos, 2007, Madrid.

Richet, D.,

La Francia moderna. El espíritu de las instituciones, Akal, 1997, Madrid.

SIEYÈs, E.,

Escritos y discursos de la Revolución, 


\section{Edgardo Rodríguez GómEZ}

CEPC, 2007. Madrid.

\section{TOUCHARD. J.,}

Historia de las ideas políticas, Tecnos, 2010, Madrid.
Van Kley, D.K,

Les origines religieuses de la Révolution française. 1560-1791, Éditions du Seuil, 2002, París. 